\title{
Strategies for Reducing the PGM Loading in High Power AEMFC Anodes
}

\author{
Travis J. Omasta, $\oplus^{1,2, *}$ Yufeng Zhang, ${ }^{2}$ Andrew M. Park, ${ }^{3, * *}$ Xiong Peng, 1,2,* \\ Bryan Pivovar, ${ }^{3, * *}$ John R. Varcoe, ${ }^{4, * *}$ and William E. Mustain $\oplus^{1,2, * *, z}$ \\ ${ }^{I}$ Department of Chemical Engineering, University of South Carolina, Columbia, South Carolina 29208, USA \\ ${ }^{2}$ Department of Chemical \& Biomolecular Engineering, University of Connecticut, Storrs, Connecticut 06269, USA \\ ${ }^{3}$ National Renewable Energy Laboratory, Golden, Colorado 80401, USA \\ ${ }^{4}$ Department of Chemistry, University of Surrey, Guildford GU2 7XH, United Kingdom
}

\begin{abstract}
Anion Exchange Membrane Fuel Cells (AEMFCs) have experienced a significant rise in attention in recent years, largely motivated by the potential to overcome the costs that have plateaued for proton exchange membrane fuel cells. However, despite significant advances in power generation, membrane conductivity, membrane stability, and catalyst activity, the vast majority of high performing AEMFCs are fabricated with a high PGM loading $\left(0.4-0.8 \mathrm{mg} \mathrm{cm}^{-2}\right)$. This work demonstrates an electrode fabrication method that reduces the anode catalyst loading by $85 \%$ while still achieving performance ca. $1 \mathrm{~W} \mathrm{~cm}^{-2}$-accomplished by designing a multilayered electrode comprised of an optimized ionomer:carbon:PGM ratio catalyst layer coupled with a hydrophobic microporous layer. If paired with a high-performing PGM-free cathode, this new anode shows the potential to meet existing DOE PGM loading and performance targets.

(C) The Author(s) 2018. Published by ECS. This is an open access article distributed under the terms of the Creative Commons Attribution 4.0 License (CC BY, http://creativecommons.org/licenses/by/4.0/), which permits unrestricted reuse of the work in any medium, provided the original work is properly cited. [DOI: 10.1149/2.1401809jes]

(c) BY
\end{abstract}

Manuscript submitted April 24, 2018; revised manuscript received June 13, 2018. Published June 21, 2018. This was Paper 1754 presented at the Seattle, Washington Meeting of the Society, May 13-17, 2018.

Anion exchange membrane fuel cells (AEMFCs) have received significant attention in recent years as a potentially lower cost electrochemical energy conversion device than proton exchange membrane fuel cells (PEMFCs). ${ }^{1-3}$ There have been several major advancements in the materials and operational understanding of the AEMFC in the past few years, which have allowed AEMFCs to close the performance gap with PEMFCs. Improvements in membrane stability and conductivity have been at the forefront of the material improvements, with conductivities rivaling Nafion, ${ }^{4-10}$ and an increasing number of membranes showing stability in highly alkaline environments (up to $2 \mathrm{M}$ $\mathrm{KOH}$ at $80^{\circ} \mathrm{C}$ ) for 100 s or even 1000 s of hours. ${ }^{8-13}$ Additionally, catalyst layer engineering that allows for improved water management, both on the macro-scale ${ }^{14}$ and on the micro-scale, ${ }^{15}$ has led to AEMFCs that are able to achieve peak power densities nearing $2 \mathrm{~W} \mathrm{~cm}^{-2}$ and demonstrate operational stability exceeding 500 hours. These are crucial steps toward the realization of commercially viable AEMFCs; however, there remain additional hurdles to overcome, specifically AEMFCs with low platinum group metal (PGM) loadings that are able to not only achieve high power densities but sustain them over long term operation. ${ }^{12}$

In order to reduce the PGM loading in operating AEMFCs, there will need to be at least some development of non-PGM catalysts. Due to differences in the water dissociation behavior in alkaline media, ${ }^{16}$ the kinetics for the hydrogen oxidation reaction are hindered in alkaline media compared to acid media. ${ }^{17}$ The opposite is true of the oxygen reduction reaction at the cathode; therefore, it is more likely that the AEMFC will see a high performance PGM-free cathode electrode. Indeed, some very promising catalysts have already been identified. ${ }^{3,18-23}$ However, at the AEMFC anode, it is very likely (akin to the PEMFC cathode) that it will be difficult to move completely away from PGM-based catalysts, though this is presently an active area for research. ${ }^{24,25}$ Therefore, it is important for researchers in the field to investigate electrode compositions that allow for reduced catalyst loading - the most active hydrogen evolution catalyst known today is $\mathrm{PtRu}^{26}$ - while still allowing for the water produced during the hydrogen oxidation to be properly managed, a crucial step in the successful operation of AEMFCs. ${ }^{3,14,15}$ Properties of the catalyst layer such as structure, thickness, porosity, component chemistry, and

\footnotetext{
*Electrochemical Society Student Member.

**Electrochemical Society Member.

${ }^{\mathrm{z}}$ E-mail: mustainw@mailbox.sc.edu
}

ionomer:carbon:catalyst ratio all have a significant effect on the water content and balance of the overall cell.

In this study, the influence of anode catalyst layer thickness and catalyst distribution in lower loading electrodes is investigated, with the goal of decreasing PGM loading without sacrificing performance. Several approaches are tried, including thinner catalyst layers, diluting the catalyst in the active layer as well as introducing multi-layered electrodes with a microporous layer (in various thickness ratios). The resulting catalyst layers are analyzed through their achievable current, peak power density, electrochemical surface area, hydroxide transport resistance, as well as kinetic and mass transport reaction overpotentials. Finally, performance and stability of the catalyst layers with decreased platinum group metal (PGM) loading will be shown, demonstrating an anode electrode, that when paired with a PGM free anode, could potentially meet DOE loading and performance targets.

\section{Experimental}

Ethylene tetrafluoroethylene (ETFE-BTMA) membrane synthesis.-The membrane used in this study was a quaternary ammonium functionalized ETFE polymer, prepared from commercial $25 \mu \mathrm{m}$ ETFE sheets (Nowofol Kunststoffprodukte GmbH, Germany) using a peroxidation (pre-irradiation in air) method that has been previously reported. ${ }^{6}$ The ETFE films were first subjected to a 30 $\mathrm{kGy}$ dose of electron-beam irradiation in air (4.5 MeV Dynamatron Continuous Electron Beam Unit at Synergy Health, South Marston, UK). With the irradiation step occurring in the presence of oxygen, peroxides and hydroperoxide groups are immediately created from the reaction of radicals (formed during irradiation) with $\mathrm{O}_{2}$. The peroxidated ETFE films act as a solid-state free-radical initiator for the subsequent grafting step. After irradiation, the films were transported back to the laboratory in dry ice before they were stored in a freezer at $-40^{\circ} \mathrm{C}$ (the peroxide groups are stable for around 6 months at this temperature). ${ }^{27}$

Next, the peroxide initiated ETFE films (ca. $15 \mathrm{~cm} \times 15 \mathrm{~cm}$ ) were immersed in an aqueous dispersion of VBC (vinylbenzyl chloride, 5 vol\% mixture of 3- and 4-isomers; 500 - 100 ppm tert-4-butylcatechol and $700-1100 \mathrm{ppm}$ nitromethane inhibitors, Sigma-Aldrich and used without the removal of inhibitors) in sealed vessels along with the addition of a dispersant (1 vol\% 1-octyl-2-pyrrolidone, SigmaAldrich). The solutions were purged with $\mathrm{N}_{2}$ for $2 \mathrm{~h}$ before the vessel was sealed and heated at $70^{\circ} \mathrm{C}$. After the reaction period, the films were removed from the grafting mixture and excess unreacted $\mathrm{VBC}$ and 
any poly(VBC) homopolymer (not bound to the ETFE base material) were removed by washing the films in toluene (reagent grade, Fisher Scientific). The resulting intermediate ETFE- $g$-poly(VBC) films were subsequently dried at $70^{\circ} \mathrm{C}$ for $5 \mathrm{~h}$ in a vacuum oven to remove all traces of solvent.

To quaternize, the intermediate films were then submerged in an aqueous trimethylamine solution (TMA, $45 \mathrm{wt} \%$, Sigma-Aldrich) for $24 \mathrm{~h}$ at ambient temperature. Afterwards, the films were washed with, and then heated in, 18.2 $\mathrm{M} \Omega$ deionized (DI) water in order to remove any excess TMA. Final conversion to chloride-anion-form ETFE- $g$-poly(vinylbenzyl trimethylammonium) (ETFE-BTMA) anion exchange membranes (AEMs) was performed by submersion of the membranes in aqueous $\mathrm{NaCl}(1 \mathrm{M})$ for $15 \mathrm{~h}$ (with a change of $\mathrm{NaCl}$ solution during this period to ensure complete ion-exchange). The resulting AEMs were then thoroughly soaked and rinsed in water to remove any excess $\mathrm{NaCl}$-derived co- and counter-ions. The final $\operatorname{AEM}\left(\mathrm{Cl}^{-}\right)$films were stored in DI water until used in the fuel cell experiments described below.

Anion-exchange ionomer (AEI) powder synthesis.-The synthesis of the powdered AEI is summarized here and has been previously reported in detail. ${ }^{28}$ ETFE powder (Z8820X, AGC Chemicals Europe) with a particle size of approximately $25 \mu \mathrm{m}$ was dosed with $70 \mathrm{kGy}$ electron-beam radiation in air. The resulting powder was then grafted with VBC by submersion in a solution containing VBC, 2-propanol (reagent grade, Sigma-Aldrich), and Surfadone LP-100 (ISPcorp) in a volume ratio of 1.00:3.95:0.05. The mixture was purged with $\mathrm{N}_{2}$ for $2 \mathrm{~h}$, and then sealed and heated for $72 \mathrm{~h}$ at $60^{\circ} \mathrm{C}$. The resulting grafted powder was recovered by filtration, washed with toluene (reagent grade, Fisher Scientific), and dried at $50^{\circ} \mathrm{C}$ under vacuum, resulting in ETFE- $g$-poly(VBC) grafted powders. The powder was then quaternized by submersion in an aqueous TMA solution (50 wt\% TMA in water, Acros Organics) for $5 \mathrm{~h}$ at ambient temperature. The quaternized powder was washed 5 times with DI water, and then heated at $50^{\circ} \mathrm{C}$ for $18 \mathrm{~h}$ in DI water. After additional washing steps (5 more times with DI water), the powder was dried under vacuum for $5 \mathrm{~d}$ at $40^{\circ} \mathrm{C}$. The final AEI powder had an IEC of $1.24 \pm 0.06 \mathrm{mmol} \mathrm{g}^{-1}$

Electrode composition and structure.-Three different types of anode catalyst layers (CL) were fabricated in this work: 1) A single layer electrode with a "balanced" AEI:carbon:PtRu mass ratio ${ }^{15}$ of 1.0:2.5:1.5; two anodes of this type were made. The first possessed a $\mathrm{PtRu}$ catalyst loading and thickness typical of top performing AEMFCs in the literature, $0.72 \mathrm{mg}_{\mathrm{PtRu}} \mathrm{cm}^{-2}$ (denoted as BC). The second anode of this type had approximately half of the PtRu catalyst loading $\left(0.40 \mathrm{mg} \mathrm{cm}^{-2}\right)$ and thickness (denoted as “ $\frac{1}{2} \mathrm{BC}$ ”); 2) A single layer electrode with a "diluted" CL that was designed to have the same loading as $\frac{1}{2} \mathrm{BC}$, but the same thickness as BC. This was accomplished by adding Vulcan XC-72R (Cabot) to the ink in order to achieve an AEI:C:PtRu ratio of 1.0:2.5:0.75. Only one anode of this type was made; it is denoted as " $\frac{1}{2} \mathrm{D}$ "; and 3) multilayered electrodes consisting of a catalyst layer (in contact with the membrane) and a microporous layer (MPL) located between the catalyst layer and the gas diffusion layer (GDL). The MPL was comprised of AEI and Vulcan carbon in the following mass ratio, 0.417:1.0. Three anodes of this type were made. All of them were designed to have the same approximate thickness as the $\mathrm{BC}$ and $\frac{1}{2} \mathrm{D}$ anodes. The difference between them was the ratio of the catalyst layer thickness and the MPL thickness. The first anode of this type had a catalyst layer that was the same as the $\frac{1}{2} \mathrm{BC}$ anode; hence the MPL thickness was approximately the same as CL thickness and this case will be denoted "1:1 CL/MPL". The second anode of this type also had an electrode with the same composition as BC but was only $\frac{1}{4}$ of the loading; hence the MPL thickness was approximately three times the CL thickness and is denoted as "1:3 CL/MPL" in the discussion below. The third and final anode of this type again had an electrode with the same composition as $\mathrm{BC}$, but only possessed $\frac{1}{8}$ the loading; hence the MPL thickness was approximately seven times the CL thickness and is denoted as "1:7 CL/MPL".

Therefore, six distinct anode electrode compositions were produced - 2 two "single layer" electrodes, 1 "diluted" electrode and 3 "multilayer" electrodes. For each of the six compositions, a minimum of three identical anodes were tested, and representative data is reported in each case. For clarity, illustrations of each of the six electrodes are shown in Figure 1. The catalyst loading and thickness (measured at 5 locations per electrode with a micrometer, Mitutoyo MDC-SX) of each electrode are given in Table I. For all experiments, the cathode was essentially identical. The cathode $\mathrm{Pt}$ loading was $0.52 \mathrm{mg} \mathrm{cm}^{-2} \pm 0.01 \mathrm{mg} \mathrm{cm}^{-2}$, with an AEI:C:Pt of 0.625:1.5:1.0.

Electrode preparation.-The procedure to prepare the CL was always the same, regardless of the composition. An example of preparing a BC film follows. First, the AEI powder was ground with a mortar and pestle for $10 \mathrm{~min}$ to reduce the number of aggregated particles. Second, $100-150 \mathrm{mg}$ of $60 \mathrm{wt} \% \mathrm{PtRu}$ (2:1 ratio of Pt:Ru by mass) on Vulcan carbon (Alfa Aesar HiSPEC 10000, Pt nominally $40 \mathrm{wt} \%$, and $\mathrm{Ru}$, nominally $20 \mathrm{wt} \%$, supported on Vulcan XC-72R carbon) catalyst was added to the AEI along with $1 \mathrm{~mL}$ DI water and additional Vulcan carbon to achieve the desired AEI:C:PtRu ratio. The catalystAEI mixture was then ground with a mortar and pestle for $10 \mathrm{~min}$, a length of time that was selected because it invariably produced a visually and texturally homogenous slurry, suggesting that no large AEI agglomerates remained. Then, $2 \mathrm{~mL}$ of 2-propanol (Fisher Chemical Optima) was added to the mortar and ground for a further $5 \mathrm{~min}$, after which the catalyst slurry was completely transferred to a LDPE vial, and combined with an additional $7 \mathrm{~mL}$ of 2-propanol to produce a low viscosity ink. Each ink was homogenized in an ice-chilled ultrasonic bath (Fisher Scientific FS30H) for $60 \mathrm{~min}$, maintained between $5^{\circ} \mathrm{C}$ and $10^{\circ} \mathrm{C}$. The resulting inks were spray deposited onto a $25 \mathrm{~cm}^{2}$ piece of Toray TGP-H-060 GDL (with 5 wt\% PTFE wetproofing) to fabricate gas diffusion electrodes (GDEs), using an Iwata Eclipse HP-CS with $15 \mathrm{psi}_{\mathrm{g}} \mathrm{N}_{2}$ (Airgas Ultra High Purity). $5 \mathrm{~cm}^{2}$ GDEs were then cut from the larger sprayed electrode for use in the cell hardware.

MPL inks were created using the same method described above, simply without the catalyst. The AEI:C mass ratio in the MPL ink was $0.417: 1.0$. The MPL film was also sprayed using an Iwata Eclipse HP-CS with $15 \mathrm{psi}_{\mathrm{g}} \mathrm{N}_{2}$ (Airgas Ultra High Purity). In the case where the electrode had a MPL, the MPL was applied to the GDL first and allowed to dry. This was followed by deposition of the CL using the process described above.

MEA assembly and anion exchange membrane fuel cell (AEMFC) testing.-First, the GDEs and the AEM were ion exchanged from the $\mathrm{Cl}^{-}$form to the $\mathrm{OH}^{-}$form by immersion in separate baths of aqueous $\mathrm{KOH}$ ( $1 \mathrm{M}$, Fisher Chemical, pellets/certified ACS) for 60 minutes, with a solution exchange every 20 minutes to ensure complete ion-exchange. It should be noted that during the ionexchange process nearly no particles were removed from the GDEs, verifying successful adhesion of the CL and MPL films to the GDL. Prior to assembly, excess aqueous $\mathrm{KOH}$ and water were removed from the membrane and GDEs, immediately after which the set of GDEs and AEM were pressed together between two single pass serpentine graphite plates in $5 \mathrm{~cm}^{2}$ Fuel Cell Technologies hardware with no prior hot pressing of the membrane electrode assembly (MEA). The MEA was sealed and compressed with 6 mil $(152 \mu \mathrm{m})$ PTFE gaskets with $20 \%-25 \%$ pinch at $5.1 \mathrm{~N} \cdot \mathrm{m}$ torque.

Humidified $\mathrm{H}_{2}$ and $\mathrm{O}_{2}$ gas feeds were supplied to the anode and cathode, respectively, at $1.0 \mathrm{~L} \mathrm{~min}^{-1}$ from a Scribner $850 \mathrm{e}$ Fuel Cell Test Station, which was used for all testing. The gas feeds were provided without back pressure (ca. 1 atm absolute). In each experiment, the dew points of the anode and cathode reacting gases were optimized, which was achieved by iteratively adjusting the anode and cathode dew points approximately every 10 minutes, allowing the cell to equilibrate, and observing the cell response. The optimized dew 


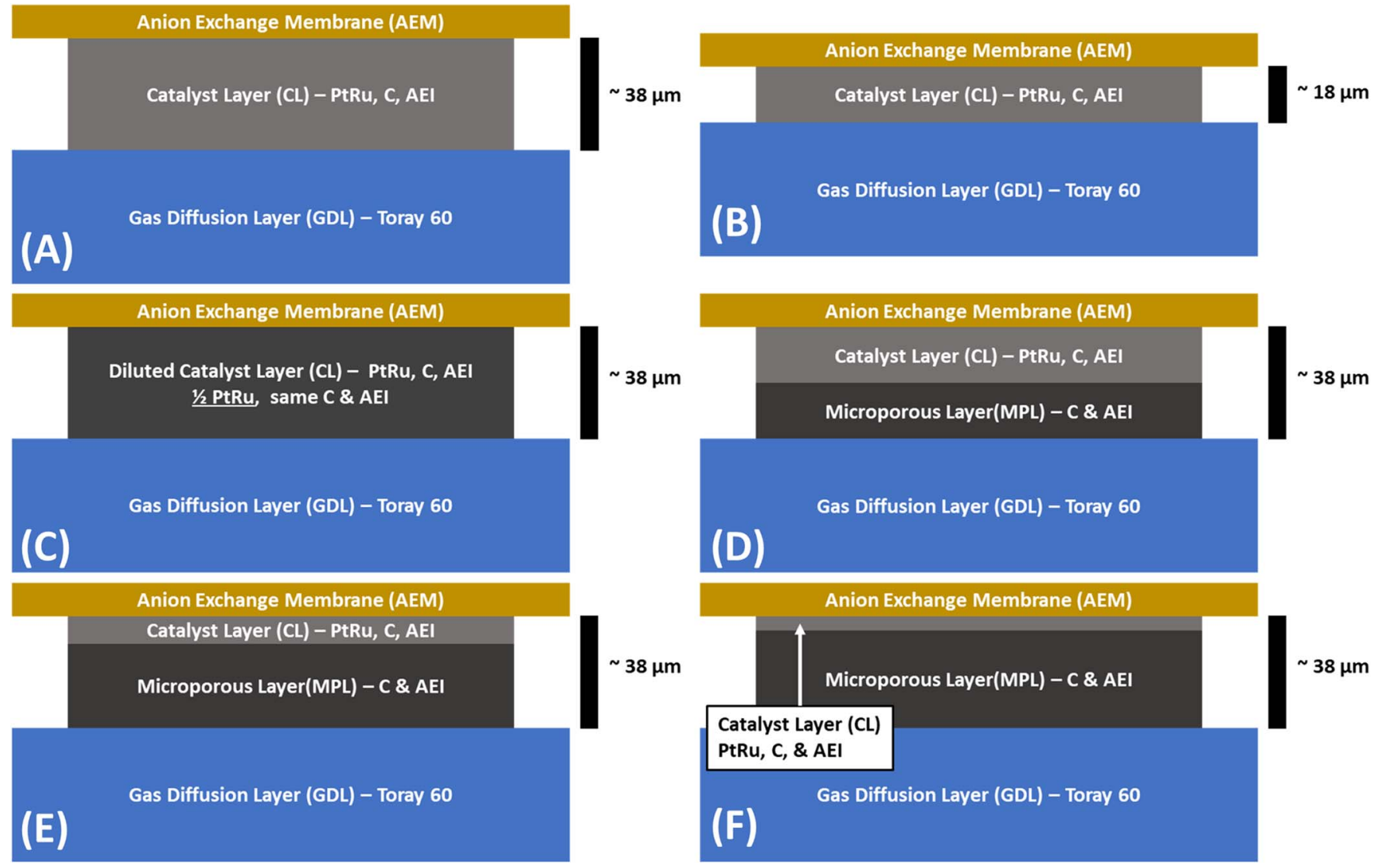

Figure 1. Diagram of the electrode layer designs used in this study: A) Standard (BC); B) $\frac{1}{2}$ thick BC ( $\frac{1}{2}$ BC, reduced loading, standard AEI:C:Pt ratio, reduced thickness) C) $\frac{1}{2}$ Diluted ( $\frac{1}{2}$ D, reduced loading, reduced AEI:C:Pt ratio, standard thickness); and Multilayer electrode (reduced loading, standard AEI:C:Pt ratio, thickness supplemented with MPL) in D) 1:1 CL/MPL, E) 1:3 CL/MPL, and F) 1:7 CL/MPL ratios.

points were selected where power and current density were maximized without sacrificing membrane hydration, which is indirectly measured by the test station in two ways: current interrupt and measuring the high frequency resistance (HFR). The optimized dew points are reported in an Anode/Cathode format. For example, noting dew points of $56 / 58$ would correspond to an anode dew point of $56^{\circ} \mathrm{C}$ and a cathode dew point of $58^{\circ} \mathrm{C}$. A cell temperature of $60^{\circ} \mathrm{C} \pm 0.1^{\circ} \mathrm{C}$ was used for all experiments and the heated gas lines following the Scribner 850e Fuel Cell Test Station were held at $5^{\circ} \mathrm{C}$ above the respective gas dew points to avoid any condensation in the lines.

All of the polarization curves shown were collected under potentiometric control at a scan rate of $10 \mathrm{mV} \mathrm{s}^{-1}$. Linear sweeps - in lieu of point-by-point collection - were used in order to better tease out flooding issues under water starved and flooded conditions. When water management issues are well controlled, there is no significant difference between point by point and linear sweep polarization curves, which was shown in our previous work for multiple high performing cells. ${ }^{14,15}$ Additionally, tests were repeated after multiple hours and varying the testing conditions to ensure stability, recoverability, and repeatability.
Measuring the electrochemically active surface area of the PtRu electrodes.-CO stripping was used to measure the electrochemical surface area (ECSA) of all electrodes after they were loaded into the AEMFC hardware. In this technique, humidified pure $\mathrm{CO}$ gas is fed to the $\mathrm{PtRu} / \mathrm{C}$ working electrode and $\mathrm{H}_{2}$ gas is fed to the $\mathrm{Pt} / \mathrm{C}$ counter electrode. $\mathrm{CO}$ adsorbs as a full monolayer on the electrode surface at low potential. The gas at the $\mathrm{PtRu} / \mathrm{C}$ electrode is switched to $\mathrm{N}_{2}$ in order to flush out any excess gas-phase $\mathrm{CO}$. Then, the electrode potential is swept in the positive direction to oxidize the $\mathrm{CO}$ to $\mathrm{CO}_{2}$. The area under the curve in the resulting voltammogram can be directly linked to the quantity of $\mathrm{CO}$, and hence the area that $\mathrm{CO}$ previously occupied on the surface.

Here, $0.2 \mathrm{~L} \mathrm{~min}^{-1} \mathrm{CO}$ was passed over the PtRu working electrode for 10 minutes while $0.2 \mathrm{~L} \mathrm{~min}^{-1} \mathrm{H}_{2}$ was continuously passed over the $\mathrm{Pt} / \mathrm{C}$ counter electrode. During the flow of $\mathrm{CO}$, the $\mathrm{PtRu} / \mathrm{C}$ electrode potential was held at a potential of $0.2 \mathrm{~V}$ vs the counter electrode in order to ensure that none of the surface $\mathrm{CO}$ was oxidized, allowing for complete adsorption of $\mathrm{CO}$ on all active sites. Following CO adsorption, $\mathrm{N}_{2}$ was purged for 30 minutes, and cyclic voltammograms were collected between 0.07 and $1.2 \mathrm{~V}$ for three cycles at $20 \mathrm{mV} / \mathrm{s}$.

Table I. Loadings and Dew Points of all cells tested in the manuscript.

\begin{tabular}{|c|c|c|c|c|c|c|}
\hline Anode Type: & $\mathrm{BC}$ & $\frac{1}{2} \mathrm{BC}$ & $\frac{1}{2} \mathrm{D}$ & 1:1 CL/MPL & 1:3 CL/MPL & 1:7 CL/MPL \\
\hline Anode PtRu Loading, $\mathrm{mg} \mathrm{cm}^{-2}$ & 0.72 & 0.40 & 0.40 & 0.40 & 0.19 & 0.11 \\
\hline Cathode Pt Loading, $\mathrm{mg} \mathrm{cm}^{-2}$ & 0.53 & 0.53 & 0.53 & 0.53 & 0.52 & 0.52 \\
\hline MPL, fraction of electrode & - & - & - & $\frac{1}{2}$ & $\frac{3}{4}$ & $\frac{7}{8}$ \\
\hline Thickness, $\mu \mathrm{m}$ & $38 \pm 1$ & $18 \pm 1$ & $38 \pm 1$ & $38 \pm 1$ & $38 \pm 1$ & $38^{8} \pm 1$ \\
\hline Optimized Dew Points, ${ }^{\circ} \mathrm{C}$ & $47 / 48$ & $53 / 53$ & $50 / 51$ & $46 / 47$ & $50 / 50$ & $52 / 53$ \\
\hline
\end{tabular}


$\mathrm{CO}$ was fully stripped from all electrochemically active platinum sites during the first cycle. The areal difference between the first and second cycle (in Watts) was then used to calculate the electrode ECSA.

\section{Quantitative Analysis of AEMFC Polarization Curves}

As the electrode composition is varied, it is important to understand not only how these changes are manifest in the cell performance, but also in fundamentals: kinetics, ohmic resistance and mass transport. Though several methods have been proposed in the literature to deconvolute polarization curves into these constituents, one of the most straightforward methodologies to apply was published by Gasteiger et $\mathrm{al}^{29}$ in 2004. Their approach was adapted for use in this work, which is briefly described below.

If the polarization of an operating fuel cell is assumed to be a result of only kinetic, ohmic, and mass transfer phenomena, the operating cell voltage at any current can be represented by:

$$
E_{\text {cell }}=E_{\text {rev }}-\eta_{\Omega}-\eta_{\mathrm{k}}-\eta_{\mathrm{MT}}
$$

where $\mathrm{E}_{\text {cell }}$ is the operating cell voltage, $\mathrm{E}_{\mathrm{rev}}$ is the thermodynamic reversible cell potential $(1.20 \mathrm{~V})$, and $\eta_{\Omega}, \eta_{\mathrm{k}}$, and $\eta_{\mathrm{MT}}$ represent the ohmic, kinetic, and mass transfer overpotentials, respectively. The first step to extracting each of the overpotentials in Equation 1 is to isolate the ohmic overpotential, which can be directly calculated at each point on the curve from the product of the high frequency resistance $\left(\mathrm{R}_{\mathrm{HFR}}\right)$ - which is measured by a frequency response analyzer built into the Scribner fuel cell test stands - and the operating current (i), as shown in Equation 2:

$$
\eta_{\Omega}=i R_{\mathrm{HFR}}
$$

The next step is to extract the kinetic overpotential, which can be done at cell voltages greater than $0.85 \mathrm{~V}$ and operating currents less than $100 \mathrm{~mA} \mathrm{~cm}^{-2}$ under the assumption that mass transfer limitations are negligible in that region. ${ }^{29}$ Under these conditions, Equation 1 can be simplified and the resulting data fit by the Tafel equation as shown in Equation:

$$
E_{\text {rev }}-E_{\text {cell }}-\eta_{\Omega}=\eta_{\mathrm{k}} \propto a+b^{*} \log (i)
$$

where $b$ is the Tafel slope. The final step of the deconvolution is to calculate the mass transfer overpotential, which is done by subtracting the kinetic and ohmic overpotentials from the reversible cell potential at all current densities:

$$
\eta_{\mathrm{MT}}=E_{\text {rev }}-\eta_{\Omega}-\eta_{\mathrm{k}}
$$

It should be noted that in this method the cell polarization due to hydroxide transport resistance within the catalyst layer is included in the mass transfer overpotential. It shows itself in the experimental data as the initial slope before the mass transport limiting current is approached. Often the electrode hydroxide transfer overpotential would be considered a component of the ohmic overpotential; however, explicitly accounting for it requires an $\mathrm{AC}$ impedance frequency sweep to measure, a technique that is not practical during a dynamic polarization experiment.

\section{Results and Discussion}

Reducing the anode catalyst loading and electrode thickness.An AEMFC was assembled with a state-of-the-art BC anode, ${ }^{15}$ Figure $1 \mathrm{~A}$, in order to provide a fair comparison for the lower loading catalyst layers since it is not only the highest performing AEMFC anode in the literature to date, it also has similar catalyst loadings to other literature reports. Therefore, advances that are made in this study are expected to be broadly applicable to the AEMFC community. Unsurprisingly, the AEMFC with the BC anode performed well (Figure 2A). It was able to support a mass transport limited current density of $4 \mathrm{~A} \mathrm{~cm}^{-2}$ and a peak power density of $1.6 \mathrm{~W} \mathrm{~cm}^{-2}$, on par with our group's previous publication with this anode. ${ }^{15}$ Deconvoluting its polarization curve, it was observed that the kinetic overpotential was always below $0.4 \mathrm{~V}$ (Figure 2B). This overpotential is within a reasonable range for fuel cell electrodes containing high activity catalysts with good utilization. The ohmic overpotential (Figure 2C) shows the expected behavior of AEMFCs, with a slight decreasing slope with increasing current. This change in the slope is caused by increased ionic conductivity in the membrane, which is facilitated by increased water uptake as the anode water production increases with increasing current from the hydrogen oxidation reaction (Equation 5).

$$
\mathrm{H}_{2}+2 \mathrm{OH}^{-} \rightarrow 2 \mathrm{H}_{2} \mathrm{O}+2 e^{-}
$$

Finally, the mass transport overpotential gradually increased with the current density until the cell passed $3 \mathrm{~A} \mathrm{~cm}^{-2}$, indicating a low hydroxide transfer resistance in the catalyst layer, and successful water management - both of which allow the cell to achieve higher currents and, in turn, higher power densities. After $3 \mathrm{~A} \mathrm{~cm}^{-2}$, the mass transport overpotential became the dominating contributor to cell polarization, as well as the achievable current and peak power. The goal of this study was to drastically lower the catalyst loading, while retaining current and power densities as close to state-of-the-art BC as possible.

The first attempt to lower the PGM catalyst loading was the $\frac{1}{2}$ $\mathrm{BC}$ anode, fabricated with an identical CL composition as the BC electrode, at approximately half the loading and thickness (Figure 1B). It would be expected that this method would greatly sacrifice the water capacity of the catalyst layer, making the cell more sensitive to water and more susceptible to flooding. Looking at the i-V and i-P curves for the $\frac{1}{2}$ BC electrode in Figure $2 \mathrm{~A}$, it is clear that reducing the catalyst layer thickness has a negative effect on both the achievable current density (now $<2 \mathrm{~A} \mathrm{~cm}^{-2}-$ less than half the value of the $\mathrm{BC}$ anode) and peak power density (only $0.8 \mathrm{~W} \mathrm{~cm}^{-2}$-also half the value of the $\mathrm{BC}$ anode).

Deconvolution of the $\frac{1}{2} \mathrm{BC}$ anode polarization curve showed near identical ohmic overpotentials (Figure 2C), and a slight increase in the kinetic overpotential (Figure $3 \mathrm{~B}$ ) compared to the $\mathrm{BC}$ anode. The most notable change when comparing the $\frac{1}{2} \mathrm{BC}$ and $\mathrm{BC}$ anodes is the significant increase in the mass transfer overpotential (Figure 3D) over the entire current range. At higher currents, the increased mass transport resistance is not too surprising since the decreased water capacity of the anode would make it more susceptible to flooding. However, it was somewhat surprising that the mass transport resistance at low current densities, which shows the resistance to ionic movement in the catalyst layers also decreased. This suggests that hydroxide transport at the cathode in the $\frac{1}{2} \mathrm{BC}$ cell is suffering. In short, the same reduced water capacity of the $\frac{1}{2} \mathrm{BC}$ anode compared to the $\mathrm{BC}$ anode that is responsible for premature flooding also can limit the amount of water that is absorbed by the membrane and hence amount of water that is supplied to the cathode. Experimental support for reduced membrane water and reduced water transport to the cathode are higher membrane resistance for $\frac{1}{2}$ BC compared to BC (Figure 2C) as well as the higher dew points that were needed to optimize the cell performance (Table I). In summary, comparing the BC and $\frac{1}{2} \mathrm{BC}$ anode suggests that simply decreasing the CL thickness might not be the most productive way to decrease the catalyst loading. Therefore, pathways to decrease loading while maintaining the catalyst layer thickness were explored.

Reducing the catalyst loading while maintaining the electrode thickness. - The first approach to reduce the catalyst loading while maintaining the electrode thickness was to add excess Vulcan carbon to the catalyst formulation while maintaining the AEI:C ratio, essentially diluting the catalyst layer. The resulting $\frac{1}{2} \mathrm{D}$ electrode had the same the carbon and ionomer loading, and similar thickness, as the BC anode, while the PGM catalyst loading was approximately half (Figure 1C).

From the i-V and i-P curves (Figure 2A), it can be seen that maintaining the anode thickness at the reduced catalyst loading $\left(\frac{1}{2} \mathrm{D}\right)$ was more effective than simply applying a thinner layer $\left(\frac{1}{2} \mathrm{BC}\right)$. The $\frac{1}{2} \mathrm{D}$ anode was able to sustain a current density $50 \%$ higher than the $\frac{1}{2} \mathrm{BC}$ anode, approaching $3 \mathrm{~A} \mathrm{~cm}^{-2}$. The $\frac{1}{2} \mathrm{D}$ anode also generated a 

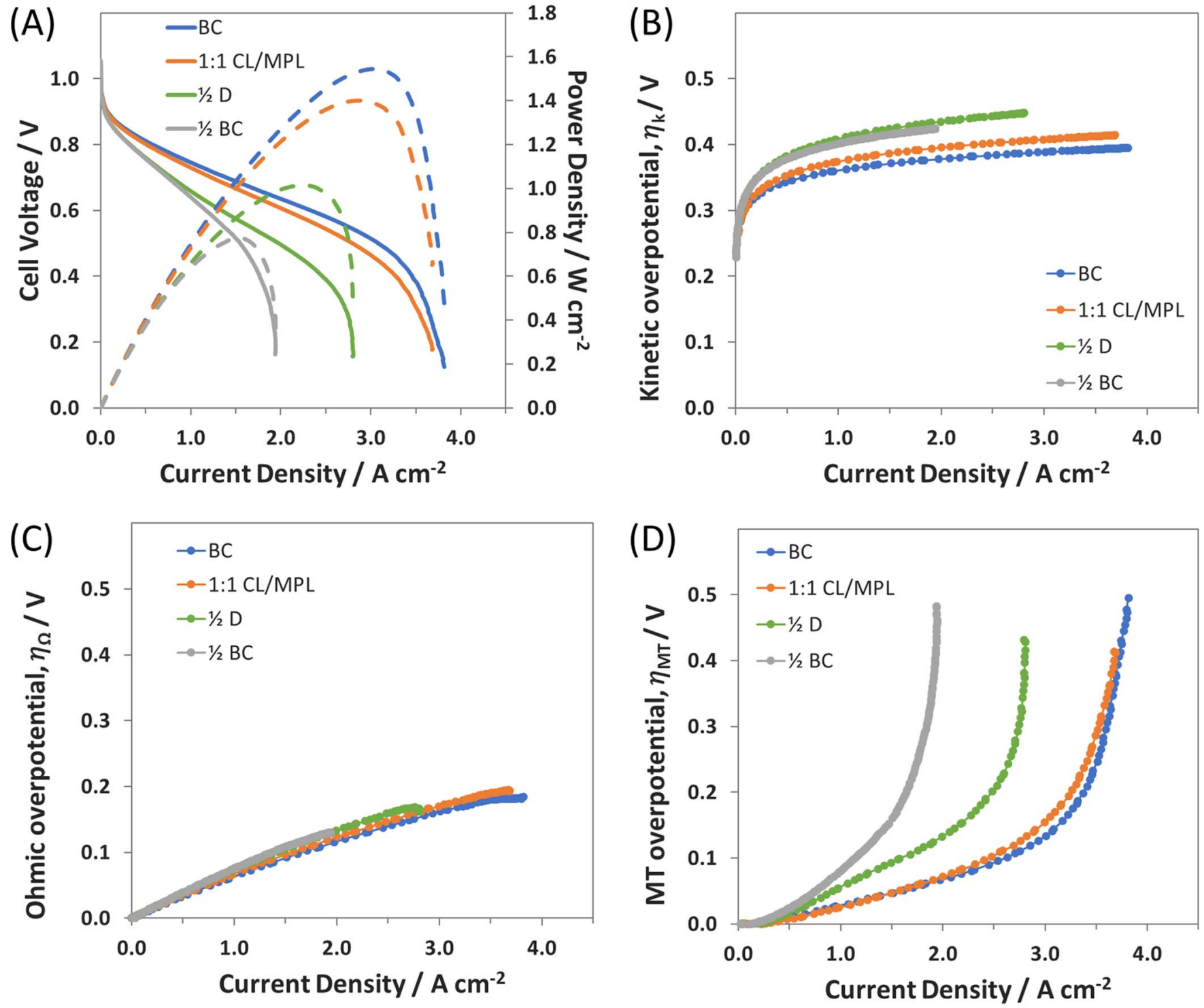

Figure 2. A) i-V and i-P curves for the Standard BC anode, 1:1 CL/MPL, Diluted ( $\left.\frac{1}{2} \mathrm{D}\right)$, and $\frac{1}{2}$ Thick $\left(\frac{1}{2} \mathrm{BC}\right)$, electrode and cell details provided in Table I; Overpotentials for the $\mathrm{i}-\mathrm{V}$ curves are deconvoluted into their B) mass transfer (MT), C) ohmic (HFR-free), and D) kinetic contributions.

slightly higher peak power density of $1 \mathrm{~W} \mathrm{~cm}^{-2}$, though the cell still appeared to be significantly mass transport limited (Figure 2D).

Another approach to decreasing the catalyst loading while maintaining the total electrode thickness is to create a multi-layered electrode, which is common in low-loading PEMFCs. Creation of these multi-layered electrodes consists of a CL and a catalyst free MPL, comprised of the ionomer and carbon. The CL is placed against the membrane and the MPL is deposited on the GDL. In this way, the reaction zone is still close the membrane in order to minimize any kinetic or CL ion transport losses. The MPL acts as a water buffer - providing a place for the produced water to be absorbed before it is removed by the flow in the GDL. Three such anodes were produced in this study, which are illustrated in Figures 1D-1F and their composition shown in Table I.

For the 1:1 CL/MPL, the CL was the same as the $\frac{1}{2} \mathrm{BC}$ anode. Now, a microporous layer of near equal thickness has been added in order to improve the water capacity and tolerance of the overall electrode. The performance of the 1:1 CL/MPL anode is plotted in Figure $2 \mathrm{~A}$, where it is shown to nearly match the polarization of the $\mathrm{BC}$ anode. Interestingly, the 1:1 CL/MPL electrode demonstrated a limiting current essentially the same as the $\mathrm{BC}$ electrode near $4 \mathrm{~A}$ $\mathrm{cm}^{-2}$, and impressively achieved a peak power density of $1.4 \mathrm{~W} \mathrm{~cm}^{-2}$ (as compared to $1.6 \mathrm{~W} \mathrm{~cm}^{-2}$ with $\mathrm{BC}$ ) despite containing only $55 \%$ of the PGM loading at the anode. To further analyze the 1:1 CL/MPL compared to the $\mathrm{BC}$ anode, the polarization curve was deconvoluted (Figures 2B-2D), which shows that the difference between the 1:1 CL/MPL and BC anodes are minimal in all three overpotentials, indicating an efficient utilization of the reduced catalyst content while maintaining the water management properties demonstrated by the $\mathrm{BC}$ electrode. The data from the 4 anode electrodes discussed thus far $\left(\frac{1}{2} \mathrm{BC}, \frac{1}{2} \mathrm{D}, 1: 1 \mathrm{CL} / \mathrm{MPL}\right.$, and $\left.\mathrm{BC}\right)$ solidify the assertions that maintaining the catalyst layer thickness and the AEI:C:PGM ratio in the active $\mathrm{CL}$ are essential when altering the anode loading, and show the 1:1 CL/MPL method is an electrode design able to achieve these properties.

Further reducing the catalyst loading by manipulating the CL:MPL ratio.-The near identical performance of the BC anode and 1:1 CL/MPL anode suggests that the catalyst present in the outer half of the $\mathrm{BC}$ electrode is not essential - particularly at high rates. Therefore, one possible area of interest for study is to determine how much of the CL can be removed and how decreasing the CL thickness 

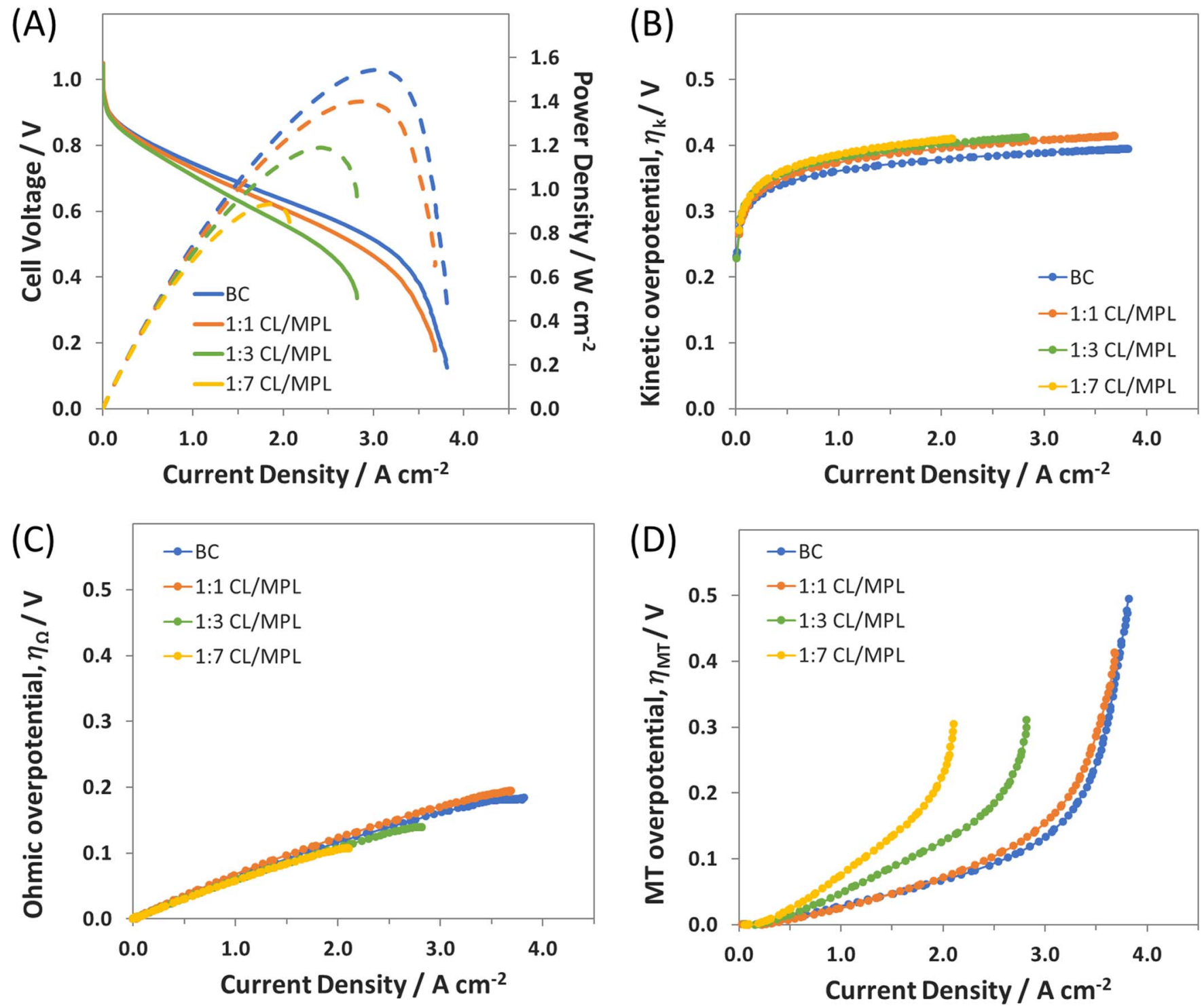

Figure 3. (A) i-V and i-P curves for all MPL based reduced anode loading cells compared with the full catalyst layer; (electrode and cell details in Table I); Overpotentials for the i-V curves are deconvoluted into their (B) mass transfer (MT), (C) ohmic, and (D) kinetic contributions.

(while maintaining the total electrode thickness through the addition of the MPL) impacts AEMFC fundamental behavior and performance. To address this, electrodes were fabricated with much thinner catalyst layers, where the approximate CL:MPL thickness ratio was 1:3 (1:3CL/MPL) and 1:7 (1:7CL/MPL).

During AEMFC testing, the 1:3 CL/MPL anode is able to retain ca. $80 \%$ of the achievable current $\left(2.8 \mathrm{~A} \mathrm{~cm}^{-2}\right)$ and peak power $(1.2 \mathrm{~W}$ $\mathrm{cm}^{-2}$ ) of the $\mathrm{BC}$ anode, despite a $75 \%$ reduction in PGM loading on the anode (Figure 3A). This lends support to the idea that the majority of the active catalyst at high rates is located close to the membrane, and that the necessary thickness and carbon content of the electrode is tied to the handling of water. When the 1:3 CL/MPL polarization curve is deconvoluted, it can be seen that the kinetic and ohmic overpotentials (Figures 3C and 3D) are nearly identical to the $\mathrm{BC}$ and 1:1 CL/MPL anodes, with the MT overpotential showing two changes. First, there was an increase in the initial MT overpotential slope, again indicative of the hydroxide transfer resistance. Second, the mass transfer limiting current is reduced, a result that is not surprising as the reactive volume of the electrode is thinner and closer to the membrane. The membrane is responsible for removing a large portion of the anode water through water uptake and back diffusion. However, as the anode thins, the rate of water uptake is constant. Therefore, the excess water both accumulates in the CL and spills over into the MPL. When the catalyst layer is thinned, the MPL may also not be able to accept water quickly enough, resulting in increased flooding in the anode, and lower performance. It also is worth noting here that the MPL is likely slightly more hydrophobic than the CL since it contains only carbon and ETFE powder - both intrinsically hydrophobic.

With the above discussion in mind, it is then not too surprising that further reducing the catalyst layer thickness in the 1:7 CL/MPL anode led to even lower achievable current and peak power (Figure 3a). On the positive side, these losses are not linear and despite containing only $15 \%$ of the PGM catalyst of the BC anode, the 1:7 CL/MPL anode was able to achieve over $50 \%$ of the current density $\left(2.2 \mathrm{~A} \mathrm{~cm}^{-2}\right)$, and $60 \%$ of the peak power density $\left(0.9 \mathrm{~W} \mathrm{~cm}^{-2}\right)$. What this means is that there is a systematic gain in the mass activity of the catalyst in the CL with decreasing CL:MPL ratio. This is shown in Table II and Figure $4 \mathrm{~A}$ - where the mass specific power achievable by the anode is increased from $2 \mathrm{~W} / \mathrm{mg}_{\mathrm{PGM}}$ in the $\mathrm{BC}$ anode to $9 \mathrm{~W} / \mathrm{mg}_{\mathrm{PGM}}$ in the $1: 7$ CL/MPL anode. It should also be noted that the 1:7 CL/MPL had a PGM loading of only $0.11 \mathrm{mg} \mathrm{cm}^{-2}$. These results show that, if paired with an appropriate PGM-free cathode, the anode reported here is more than capable of meeting at least some of the US DOE Office of 
Table II. Mass specific ECSA, current density in the kinetically controlled region, and mass specific power density of anode electrodes in the manuscript.

\begin{tabular}{lccccc}
\multicolumn{1}{c}{ Anode Type: } & BC & $\frac{1}{2} \mathrm{BC}$ & $\frac{1}{2} \mathrm{D}$ & $1: 1 \mathrm{CL} / \mathrm{MPL}$ & $1: 7 \mathrm{CL} / \mathrm{MPL}$ \\
\hline $\mathrm{ECSA}, \mathrm{m}^{2} \mathrm{~g}^{-1}$ & 51.5 & 46.5 & 48.3 & 25.7 & 30.4 \\
$\mathrm{I} @ 0.90 \mathrm{~V}, \mathrm{~mA} \mathrm{~cm}^{-2}$ & 77 & 50 & 48 & 15 & 59 \\
$\mathrm{I} @ 0.85 \mathrm{~V}, \mathrm{~mA} \mathrm{~cm}^{-2}$ & 265 & 154 & 2.5 & 240 & 190 \\
PGM Specific Power, W/mg & 2.1 & 54.9 & 47.0 & 3.3 & 8.5 \\
$\mathrm{R}_{\mathrm{OH}^{-}}, \mathrm{m} \Omega \mathrm{cm}^{2}$ & 49.4 & 58.2 & 43.9
\end{tabular}

Energy Efficiency \& Renewable Energy technical targets for polymer electrolyte membrane fuel cells, ${ }^{30}$ most notably achieving a power density of $600 \mathrm{~mW} \mathrm{~cm}^{-2}$ with a total cell PGM loading of $0.125 \mathrm{mg}$ $\mathrm{cm}^{-2}$. We believe that this is possible given the significant activity that currently surrounds non-PGM cathode catalysts in the literature. In fact, researchers have published AEMFCs with platinum free and PGM free cathodes with significant performance, even surpassing $1 \mathrm{~W} \mathrm{~cm}{ }^{-2} \cdot{ }^{20,31}$ That makes this work a significant contribution to the AEMFC field, showing the promising future and viability of this relatively immature cell variant.

Understanding the behavior of the 1:7 CL/MPL electrode CL water is important for the design of high performance, low PGM loading electrodes for AEMFCs. As discussed above, if the MPL is unable to accept water fast enough - which does appear to be the case here, meaning that MPL design is a fruitful area for future work - due to its likely intrinsic hydrophobicity from the ETFE backbone, electrode flooding is a concern. However, extending the reaction zone by employing a more diluted strategy in the thin catalyst layer portion of the electrode would be ill advised, as it was previously shown that the $\frac{1}{2}$ D diluted electrode performed relatively poorly compared to the more catalyst dense films.

In addition to the mass activity, another important practical variable that can aid with electrode design is the ECSA, which is a valuable diagnostic in electrochemical systems - typically used to understand how effectively the electrode design has assembled the triple phase boundary where the catalyst is ionically, electronically and reactively available. Measuring the ECSA of platinum-based fuel cell electrode layers in operating fuel cells via CO stripping is a well-established technique that has been used for many years in PEMFCs, and has been extended to AEMFCs. Figure 4B shows the first (orange) and second (blue) CVs for a typical CO-stripping experiment, and the results are summarized in Table II.
Interestingly, the CL/MPL electrodes show approximately half the specific ECSA $\left(\mathrm{m}^{2} \mathrm{~g}^{-1}\right)$ compared to the $\mathrm{BC}, \frac{1}{2} \mathrm{BC}$, and $\frac{1}{2} \mathrm{D}$ electrodes. This really is unexpected since not only is the normalized cell performance higher, but it was shown above that the catalyst layer closest to the membrane is likely the most active. Therefore, it would be expected that the specific ECSA of the CL/MPL anodes would be comparable or higher than the $\mathrm{BC}$ anode, and certainly be higher than the $\frac{1}{2} \mathrm{D}$ anode. The expectation is strengthened by both the deconvoluted kinetic overpotential shown in Figure 3B, along with the measured current density at $0.9 \mathrm{~V}$ and $0.85 \mathrm{~V}$ (Table II), a region of the polarization curve essentially under kinetic control. ${ }^{29} \mathrm{We}$ hypothesize that this result is the result of the hydrophobicity of the MPL film. The effect of this hydrophobic layer is to reject water and prevent the gas streams from over hydrating the catalyst layer during operation. However, during the ECSA test, there is no liquid phase water being produced by the cell, and the rejection of gas phase water by the MPL does not allow the CL to be properly hydrated during the ECSA experiment. Without proper hydration of the catalyst layer there would be areas of the electrode that contain less water and hence lower ionic conductivity and ECSA. Therefore, the ECSA measured in the presence of this hydrophobic MPL is artificially low and likely does not represent the true ECSA during cell operation. This suggests that a new method may need to be developed to measure the ECSA of these cells, and this will be investigated by our group in the future.

\section{Conclusions}

In this work, the PGM loading of AEMFC anodes was drastically reduced by replacing conventional single-layer electrodes with twolayered anode electrodes. The two-layer electrodes had a thin catalyst layer in contact with the membrane and a microporous layer (containing only the solid AEI powder and carbon) in contact with the

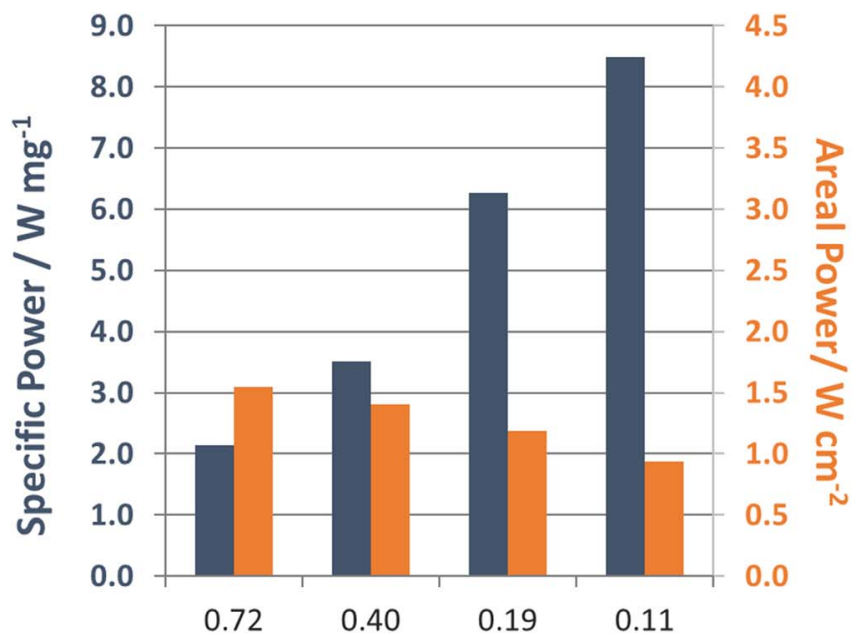

PGM Anode Loading / $\mathrm{mg} \mathrm{cm}^{-2}$

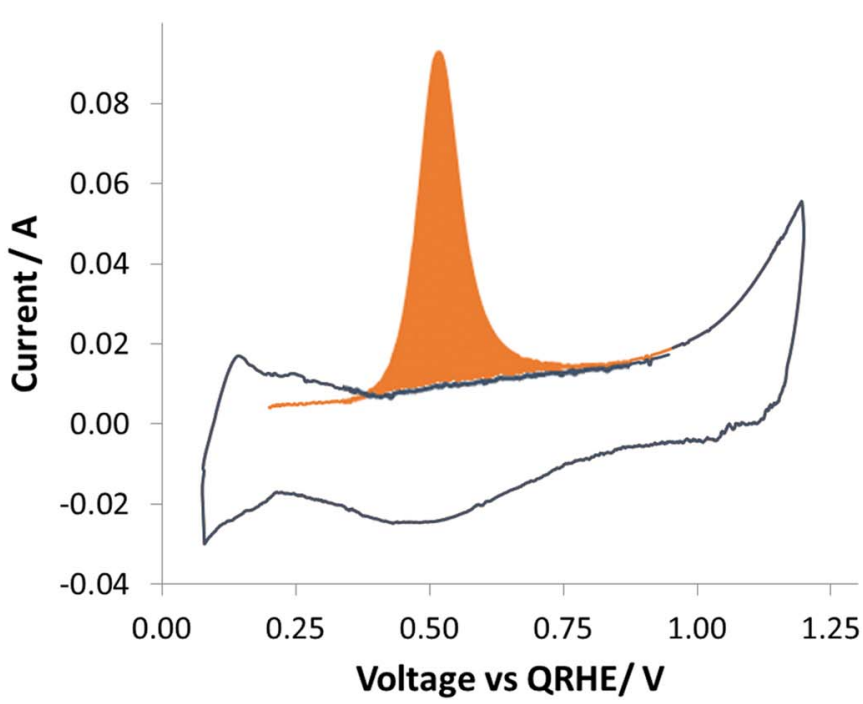

Figure 4. Mass specific diagnostic and performance of MPL modified anode electrodes; (A) PGM specific power and areal power density of CL/MPL anode AEMFCs, (electrode and cell details in Table I); (B) Representative ECSA CO stripping CV of AEMFC (assembled with BC anode, full results detailed in Table II). 
GDL. Some compositions were able to achieve peak power densities as high as $1.4 \mathrm{~W} \mathrm{~cm}^{-2}$ - comparable to state-of-the-art AEMFCs with high loading. Most importantly, application of the MPL at the anode allowed the total PGM loading of that electrode to be reduced to $0.11 \mathrm{mg} \mathrm{cm}^{-2}$ while achieving a specific power of $8.5 \mathrm{~W} / \mathrm{mg}_{\mathrm{PGM}}-\mathrm{a}$ performance that paired with a PGM-free cathode may be able to meet DOE targets.

\section{Acknowledgments}

The authors gratefully acknowledge the financial support of the US DOE Early Career Program Award Number DE-SC0010531 for the effort expended by T.J.O., X.P., and W.E.M. to perform this work as well as equipment and supplies. Y.Z. acknowledges assistance from the "Graduate Student International Cultivation of Zhejiang University" program. The diagnostic techniques and equipment at the National Renewable Energy Laboratory was supported by the U. S. Department of Energy under Contract No. DE-AC36-08GO28308. The ETFE-based materials used were developed and produced by the University Surrey team and this effort was funded by the UK's Engineering and Physical Sciences Research Council (EPSRC grant EP/M014371/1).

\section{ORCID}

Travis J. Omasta (D) https://orcid.org/0000-0002-8002-6520

William E. Mustain (D https://orcid.org/0000-0001-7804-6410

\section{References}

1. J. R. Varcoe, P. Atanassov, D. R. Dekel, A. M. Herring, M. A. Hickner, P. A. Kohl A. R. Kucernak, W. E. Mustain, K. Nijmeijer, K. Scott, T. Xu, and L. Zhuang, Energy Environ. Sci., 7, 3135 (2014).

2. B. P. Setzler, Z. Zhuang, J. A. Wittkopf, and Y. Yan, Nat. Nanotechnol., 11, 1020 (2016).

3. S. Gottesfeld, D. R. Dekel, M. Page, C. Bae, Y. Yan, P. Zelenay, and Y. S. Kim, J. Power Sources, 375, 170 (2018).

4. T. P. Pandey, A. M. Maes, H. N. Sarode, B. D. Peters, S. Lavina, K. Vezzù Y. Yang, S. D. Poynton, J. R. Varcoe, S. Seifert, M. W. Liberatore, V. Di Noto, and A. M. Herring, Phys. Chem. Chem. Phys., 17, 4367 (2015).

5. T. P. Pandey, H. N. Sarode, Y. Yang, Y. Yang, K. Vezzù, V. Di Noto, S. Seifert, D. M. Knauss, M. W. Liberatore, and A. M. Herring, J. Electrochem. Soc., 163 H513 (2016).
6. L. Q. Wang, E. Magliocca, E. L. Cunningham, W. E. Mustain, S. D. Poynton, R. Escudero-Cid, M. M. Nasef, J. Ponce-González, R. Bance-Souahli, R. C. T. Slade, D. K. Whelligan, and J. R. Varcoe, Green Chem., 19, 831 (2017).

7. L. Wang, J. J. Brink, Y. Liu, A. M. Herring, J. Ponce-González, D. K. Whelligan, and J. R. Varcoe, Energy Environ. Sci., 2154 (2017).

8. J. Ponce-González, D. K. Whelligan, L. Wang, R. Bance-Soualhi, Y. Wang, Y. Peng, H. Peng, D. C. Apperley, H. N. Sarode, T. P. Pandey, A. G. Divekar, S. Seifert, A. M. Herring, L. Zhuang, and J. R. Varcoe, Energy Environ. Sci., 9, 3724 (2016).

9. A. M. Park, Z. R. Owczarczyk, L. E. Garner, A. C. Yang-Neyerlin, H. Long, C. M. Antunes, M. R. Sturgeon, M. J. Lindell, S. J. Hamrock, M. Yandrasits, and B. S. Pivovar, ECS Trans., 80, 957 (2017).

10. R. Espiritu, M. Mamlouk, and K. Scott, Int. J. Hydrogen Energy, 41, 1120 (2016).

11. C. Chen, J. Pan, J. Han, Y. Wang, L. Zhu, M. A. Hickner, and L. Zhuang, J. Mater Chem. A, 4, 4071 (2016)

12. D. R. Dekel, J. Power Sources, 375, 158 (2018).

13. B. S. Pivovar, DOE Hydrogen, and AMR Fuel Cells Program, (2017)

14. T. J. Omasta, L. Wang, X. Peng, C. A. Lewis, J. R. Varcoe, and W. E. Mustain, J. Power Sources, 375, 205 (2018)

15. T. J. Omasta, A. M. Park, J. M. Lamanna, Y. Zhang, X. Peng, L. Wang, D. L. Jacobson, J. R. Varcoe, D. S. Hussey, B. S. Pivovar, and W. E. Mustain, Energy Environ. Sci., 11, 551 (2018).

16. I. Ledezma-Yanez, W. D. Z. Wallace, P. Sebastián-Pascual, V. Climent, J. M. Feliu, and M. T. M. Koper, Nat. Energy, 2, 1 (2017).

17. J. Durst, A. Siebel, C. Simon, F. Hasché, J. Herranz, and H. A. Gasteiger, Energy Environ. Sci., 7, 2255 (2014)

18. Z. Zhuang, S. A. Giles, J. Zheng, G. R. Jenness, S. Caratzoulas, D. G. Vlachos, and Y. Yan, Nat. Commun., 7, 1 (2016).

19. R. Gokhale, Y. Chen, A. Serov, K. Artyushkova, and P. Atanassov, Electrochem. commun., 72, 140 (2016)

20. L. Wang, J. J. Brink, and J. R. Varcoe, Chem. Commun., 53, 11771 (2017).

21. H. T. Chung, J. H. Won, and P. Zelenay, Nat. Commun., 4, 1922 (2013).

22. M. Alesker, M. Page, M. Shviro, Y. Paska, G. Gershinsky, D. R. Dekel, and D. Zitoun, J. Power Sources, 304, 332 (2016).

23. H. A. Miller, F. Vizza, M. Marelli, A. Zadick, L. Dubau, M. Chatenet, S. Geiger, S. Cherevko, H. Doan, R. K. Pavlicek, S. Mukerjee, and D. R. Dekel, Nano Energy, 33, 293 (2017).

24. S. Lu, J. Pan, A. Huang, L. Zhuang, and J. Lu, Proc. Natl. Acad. Sci., 105, 20611 (2008).

25. S. Gu, W. Sheng, R. Cai, S. M. Alia, S. Song, K. O. Jensen, and Y. Yan, Chem Commun., 49, 131 (2013).

26. Y. Wang, G. Wang, G. Li, B. Huang, J. Pan, Q. Liu, J. Han, L. Xiao, J. Lu, and L. Zhuang, Energy Environ. Sci., 8, 177 (2015).

27. J. P. Kizewski, N. H. Mudri, and J. R. Varcoe, Radiat. Phys. Chem., 89, 64 (2013).

28. S. D. Poynton, R. C. T. Slade, T. J. Omasta, W. E. Mustain, R. Escudero-Cid, P. Ocón, and J. R. Varcoe, J. Mater. Chem. A, 2, 5124 (2014).

29. H. A. Gasteiger, J. E. Panels, and S. G. Yan, J. Power Sources, 127, 162 (2004).

30. https://energy.gov/eere/fuelcells/doe-technical-targets-polymer-electrolytemembrane-fuel-cell-components.

31. X. Peng, T. J. Omasta, J. M. Roller, and W. E. Mustain, Front. Energy, 14, 299 (2017) 